\title{
The Impact of Home Safety on Sleep in a Latin American country.
}

\author{
Salvia, A.; Rodríguez Espinola, S.; Simonelli, G; \\ Vigo, D.
}

Cita:

Salvia, A.; Rodríguez Espinola, S.; Simonelli, G; Vigo, D. (2015). The Impact of Home Safety on Sleep in a Latin American country. Sleep Health: Journal of the National Sleep Foundation,.

Dirección estable: https://www.aacademica.org/agustin.salvia/331 ARK: https://n2t.net/ark:/13683/pnKz/byy 


\title{
The impact of home safety on sleep in a Latin American country
}

\author{
Guido Simonelli, MD ${ }^{\mathrm{a}, \mathrm{b}}$, Sanjay R. Patel, MD ${ }^{\mathrm{b}, \mathrm{c}}$, Solange Rodríguez-Espínola, $\mathrm{PhD}^{\mathrm{d}}$, \\ Daniel Pérez-Chada, MD ${ }^{\mathrm{e}}$, Agustín Salvia, PhD, MS ${ }^{\mathrm{d}}$, \\ Daniel P. Cardinali, MD, PhD ${ }^{\mathrm{a}}$, Daniel E. Vigo, MD, PhD ${ }^{\mathrm{a}, *}$
}

\footnotetext{
a Applied Neuroscience Laboratory, Institute for Biomedical Research (BIOMED), School of Medical Sciences, Pontifical Catholic University of Argentina, and the National Scientific and Technical Research Council (CONICET), Buenos Aires, Argentina

${ }^{\mathrm{b}}$ Division of Sleep and Circadian Disorders, Brigham and Women's Hospital, Boston, MA

c Division of Pulmonary, Critical Care and Sleep Medicine, Beth Israel Deaconess Medical Center, Harvard Medical School, Boston, MA

d Observatorio de la Deuda Social Argentina, Pontificia Universidad Católica Argentina, Consejo Nacional de Investigaciones Científicas y Técnicas, Buenos Aires, Argentina

e Pulmonary Division, Department of Internal Medicine, Hospital Universitario Austral, Buenos Aires, Argentina
}

\section{A R T I C L E I N F O}

\section{Article history:}

Received 19 November 2014

Received in revised form 13 February 2015

Accepted 16 February 2015

Available online $\mathrm{xxxx}$

\begin{abstract}
A B S T R A C T
Objectives: We sought to assess the impact of feelings of safety in one's neighborhood and home on sleep quality and sleep duration.

Design: The design is a cross-sectional survey using face-to-face interviews, as part of the Argentine Social Debt Observatory assessment.

Setting: The setting is a nationwide data from Argentina.

Participants: There are 5636 participants aged 18 years and older. Intervention (if any): $\mathrm{N} / \mathrm{A}$.

Measurements: The relationships between both subjective sleep quality and self-reported sleep duration, categorized as short ( $<7$ hours), normal ( $7-8$ hours), and long ( $>8$ hours) with safety in one's neighborhood and one's home, were analyzed. Age, sex, obesity, neighborhood socioeconomic status, and education were included as covariates.

Results: Feeling unsafe in one's home was strongly associated with poorer sleep quality and with short sleep duration. Feeling unsafe in one's neighborhood was initially associated with reduced sleep quality but was no longer significant after controlling for home safety. In contrast, we found no correlation between safety measures and long sleep. In analyses stratified by sex, feeling unsafe in one's home was associated with poor sleep quality in women but not in men.

Conclusions: Our findings suggest that safety in the home has an important effect on both sleep quality and duration, particularly among women. In contrast, after accounting for safety in the home, neighborhood safety does not impact sleep. Further research is warranted to identify mechanisms underlying the sex differences in susceptibility to poor sleep quality and shorter sleep duration, as well as to assess whether interventions addressing safety in the home can be used to improve sleep and overall health.
\end{abstract}

(c) 2015 National Sleep Foundation. Published by Elsevier Inc. All rights reserved.

\footnotetext{
Studies were supported by grants from the Agencia Nacional de Promoción Científica y Tecnológica, Buenos Aires, Argentina (PICT 2010-2195, PICT 2012-0984, and PICT Start-Up 2013-0710). DEV and DPC are Research Career Awardees from the Argentine Research Council (CONICET). GS is currently a Research Associate at the Centre for Military Psychiatry and Neuroscience Research, Walter Reed Army Institute of Research (United States) supported by the National Research Council Research Associateship Program.

* Corresponding author at: Facultad de Ciencias Médicas, Pontificia Universidad Católica Argentina, Alicia Moreau de Justo 1500, $4^{\circ}$ piso C1107AAZ, Ciudad Autónoma de Buenos Aires, República Argentina, Argentina. Tel.: + 54114349 0200x1152.

E-mail address: dvigo@conicet.gov.ar (D.E. Vigo).
}

\section{Introduction}

Several studies have established an association between neighborhood characteristics and health, especially on cardiovascular disease. ${ }^{1-4}$ Those living in disadvantaged neighborhoods have a higher incidence of cardiovascular events, even after controlling for individual-level factors. ${ }^{4-6}$ Neighborhood characteristics often studied include walkability, and access to healthy food, as well as social and physical environmental factors such as crime, social cohesion, noise, and aesthetic quality. ${ }^{4}$ In terms of the latter, some authors argue that fear of crime as well as crime itself may be mediators of the effect of the physical environment (eg, litter, contamination, abandoned buildings, etc) on public health. ${ }^{7}$ 
Neighborhood environment has been shown to be associated with classic cardiovascular risk factors such as diabetes, hypertension, and obesity, ${ }^{4,8-13}$ as well as negative mental health outcomes. ${ }^{14,15}$ Interestingly, most of this association persists after adjusting for behavioral and biomedical risks factors, suggesting that other mediators are involved. Poor sleep has been increasingly identified as an independent risk factor for cardiovascular disease as well as for cardiovascular risk factors including obesity, diabetes, and hypertension. ${ }^{16-19,8}$ Disturbed sleep has been also linked to depression. ${ }^{20}$ If neighborhood characteristics impact sleep, sleep disturbances and poor sleep quality may be one of the mechanisms through which neighborhoods affect health.

Three studies have examined neighborhood and sleep in relationship to obstructive sleep apnea risk. Those studies have shown that an adverse neighborhood environment increases the risk of obstructive sleep apnea in children. ${ }^{21-23}$ Furthermore, this increased risk is independent of obesity, ethnicity, and socioeconomic status (SES) ${ }^{21,22}$ Four studies have found that disadvantaged neighborhoods are associated with poor sleep quality and short self-reported sleep in United States. ${ }^{24-27}$ Nevertheless, those studies did not account for home safety, only focusing on neighborhood environment as a whole.

A previous study from our group found that sleep quality in a slum setting can be improved with a low-cost housing intervention, and those changes were sustained over a period of at least 6 months. ${ }^{28}$ This study raised questions about the impact of the psychosocial and physical neighborhood environment on sleep when provided a safe home environment for sleeping.

In recent years in Latin America, safety from crime has become a major concern for the general population. According to Latinobarómetro, ${ }^{29}$ the proportion of the population of Latin America that reports crime as their primary social concern rose from $5 \%$ in 1994 to $27 \%$ in 2010 . Indeed, over the last 15 years, crime perception displaced unemployment as the most important concern in the region. ${ }^{29}$

Fear of crime and feelings of insecurity have been extensively studied in the social sciences. Some authors consider public insecurity as a direct function of threats and vulnerabilities exposed by the risk of becoming a victim of crime. ${ }^{30}$ In this context, adverse social environment may create feelings of insecurity, which may impair the ability of residents to initiate and/or maintain sleep. ${ }^{31,32}$

The purpose of this study was to examine the relationship between sleep quality and quantity and perceived crime safety in a Latin American country (Argentina). We analyzed data from the 2012 Argentine Social Debt Observatory (ASDO), a nationwide survey. To our knowledge, this is the first nationwide survey in a South American country that included the aforementioned factors as a whole and the second in Latin America to explore neighborhood safety and sleep quality specifically. ${ }^{33}$

\section{Participants and methods}

\section{Participants and design}

All analyses use data from the 2012 ASDO, a nationwide probability sample of 5766 adults residing in Argentina aged 18 years and older. Participants were selected by multistage cluster random sampling based on urban agglomeration, housing conditions, and SES. In the first stage, demographic criteria were used to select the urban agglomerations (by geographic region and size). Second, stratified random sampling was used in conjunction with a variableradius plot, with probability proportional to the size of the population aged 18 years and older. At the third stage, random systematic sampling was used to select houses inside the radius plot. A trained interviewer visited the houses, and individuals were invited to participate from each house, randomly selected through a quota system of age and sex. A total of 5636 individuals (46.4\% men and 53.6\% women) participated in the survey. For this analysis, all responses were weighted to reflect each subgroup's actual proportion in the overall Argentine population. The protocol was approved by an Institutional Review Board at Pontificia Universidad Católica Argentina, and all participating subjects provided oral informed consent.

\section{Data}

Neighborhood and house safety: Participants were asked to rate separately their neighborhood and house as "rather safe from crime" (0) or "rather unsafe from crime" (1).

Sleep quality: Sleep quality was measured with the following question taken from the Spanish version of the Pittsburgh Sleep Quality Index (PSQI): “¿Cómo califacaría en general su calidad de sueño de los últimos 30 días?" or "How would you rate your sleep quality overall for the past 30 days?" Possible answers rated from 0 ("very bad") to 3 ("very good"). Sleep quality for analysis purposes was dichotomized as "good sleep quality" ("very good" and "good") (0) and "poor sleep quality" ("poor" and "very poor") (1).

Sleep duration: Questions regarding sleep included bedtime (lights off), rise time, and latency. Total sleep time was derived from the responses to these questions as nocturnal sleep (rise time to bedtime), latency, and categorized as short ( $<7$ hours), average (7-8 hours), or long (>8 hours).

Demographics: Age was categorized in 5 categories (18-29, 30-39, $40-49,50-64$, and $\geq 65$ years). Sex was obtained by self-report.

Education: Participants reported the number of years spent attending formal education. This variable was modeled continuously.

Neighborhood type: Based on structural aspects of the neighborhood and level of urbanization (street light, paved streets, land ownership, schools and hospitals in the area), neighborhoods were classified into 2 categories: "slums" and "low- and middle-income neighborhoods".

Obesity: Self-reported height and weight were included in the questionnaire. Body mass index (BMI) was calculated. Participants were categorized as obese (BMI, $\geq 30 \mathrm{~kg} / \mathrm{m}^{2}$ ) and nonobese (BMI, $<30 \mathrm{~kg} / \mathrm{m}^{2}$ ).

\section{Statistical analysis}

Data are shown as frequency (percentage) for categorical variables and mean (SD) for numerical variables. Sleep quality and sleep duration were modeled separately as dependent variables. Binary logistic regression was used to model sleep quality, whereas multinomial logistic regression was used to model sleep duration. Three models were used for each analysis; the first model was adjusted for sex, age, education, neighborhood type, and obesity. In model 2 , neighborhood safety was added; and, in the final model, home safety was added to understand how much of the sleep association with neighborhood safety was explained by a sense of security in their home. A safety-by-sex interaction term was added to model 3 for both home and neighborhood safety to assess for evidence of effect modification. Where this interaction term was statistically significant $(P<.05)$, sex stratified models were generated to better understand the impact of safety on sleep by sex.

\section{Results}

Characteristics of the sample are displayed in Table 1 stratified by neighborhood and home safety. Participants who provided incomplete data on our variables of interest $(n=130)$ were excluded 
Table 1

Sample characteristics by neighborhood and home safety.

\begin{tabular}{|c|c|c|c|c|}
\hline & Unsafe neighborhood $(\mathrm{n}=2835)$ & Safe neighborhood $(\mathrm{n}=2724)$ & Unsafe home $(\mathrm{n}=1550)$ & Safe home $(n=4009)$ \\
\hline Age (y) & $43(17)$ & $44(18)$ & $44(18)$ & $44(18)$ \\
\hline Men & $1289(45.5 \%)$ & $1289(47.3 \%)$ & $664(42.9 \%)$ & 1909 (47.6\%) \\
\hline Women & $1546(54.5 \%)$ & $1435(52.7 \%)$ & $886(57.1 \%)$ & $2100(52.4 \%)$ \\
\hline Non-obese & $2245(79.2 \%)$ & $2196(80.61 \%)$ & $1216(78.45 \%)$ & $3225(80.4 \%)$ \\
\hline Obese & $590(20.8 \%)$ & $528(19.39 \%)$ & $334(21.5 \%)$ & $784(19.6 \%)$ \\
\hline Education (y in school) & $10.69(3.58)$ & $11.47(3.91)$ & $10.35(3.48)$ & $11.36(3.83)$ \\
\hline Neighborhood non-slum & $2702(95.3 \%)$ & $2641(96.9 \%)$ & $1456(93.9 \%)$ & 3887 (96.9\%) \\
\hline Neighborhood slum & $133(4.7 \%)$ & $84(3.1 \%)$ & $95(6.1 \%)$ & $123(3.1 \%)$ \\
\hline Unsafe neighborhood & - & - & $1488(96.0 \%)$ & 1347 (33.6\%) \\
\hline Safe neighborhood & - & - & $62(4.0 \%)$ & 2657 (66.4\%) \\
\hline Unsafe home & 1488 (52.5\%) & $62(2.3 \%)$ & - & - \\
\hline Safe home & 1347 (47.5\%) & 2657 (97.7\%) & - & - \\
\hline Sleep duration (h) & $7.50(1.41)$ & $7.47(1.43)$ & $7.52(1.41)$ & $7.47(1.42)$ \\
\hline$<7 \mathrm{~h}$ & $1258(44.4 \%)$ & $1241(45.5 \%)$ & 702 (45.3\%) & 1791 (44.7\%) \\
\hline $7-8 \mathrm{~h}$ & $699(24.6 \%)$ & $673(24.7 \%)$ & 358 (23.1\%) & $1018(25.4 \%)$ \\
\hline$>8 \mathrm{~h}$ & $879(31.0 \%)$ & $811(29.8 \%)$ & $490(31.6 \%)$ & 1200 (29.9\%) \\
\hline Good sleep quality & $2336(82.4 \%)$ & $2357(86.5 \%)$ & 1245 (80.3\%) & 3449 (86.0\%) \\
\hline Poor sleep quality & $499(17.6 \%)$ & 367 (13.5\%) & $306(19.7 \%)$ & $560(14.0 \%)$ \\
\hline
\end{tabular}

from analyses. Overall, sleep quality was good in $84.5 \%(n=4764)$ and poor in $15.5 \%(n=872)$. The mean sleep duration was $7.49 \pm$ 1.42 hours. When dividing sleep into short and long, we found $44.8 \%$ (2523) with short sleep and 30.5\% (1720) with long sleep. A total of $51.0 \%$ felt unsafe in their neighborhood, and $27.9 \%$ felt unsafe in their home.

Table 2 shows the impact of safety concerns on sleep quality. Adjusting for age, sex, education, neighborhood type, and obesity, an unsafe neighborhood was associated with an increased odds of poor sleep (odds ratio $[O R]=1.30, P<.001$ ). After accounting for house safety, the association between neighborhood safety and sleep quality was fully attenuated. Instead, a stronger association between house safety and poor sleep quality was observed $(\mathrm{OR}=1.32, P=.004)$.

Tests for effect modification found that the impact of home safety on sleep quality differed significantly by sex ( $O R=1.40, P=.037)$. Table 3 shows the impact of safety concerns on sleep quality stratified by sex. In the fully adjusted model, we found that women had $38 \%$ greater odds of being poor sleepers when feeling unsafe in their home $(P=.01)$, whereas we found no effect of safety on sleep quality in men.

Table 4 shows the impact of safety concerns on sleep duration. In our fully adjusted model, we found that participants who felt unsafe at their homes were $23 \%$ more likely to be short sleepers than intermediate duration sleepers $(P=.02)$. We did not find a significant relationship between neighborhood safety and sleep duration. Interestingly, when looking at neighborhood characteristics, we found that slum dwellers were $43 \%$ less likely to be short sleepers compared with participants from low-/middle-income neighborhoods.

\section{Discussion}

Our primary finding is that sleep quality is associated with feelings of safety both in one's neighborhood and one's home independent of such potential confounders as age, sex, education, neighborhood type, and obesity. In our fully adjusted models, feeling unsafe in one's home was associated with poor sleep quality and seemed to explain the association between neighborhood safety and sleep quality. Feeling unsafe in one's home was also associated with a higher risk of short sleep duration.

Sleep occurs when one feels sufficiently safe and secure to downregulate vigilance and alertness. ${ }^{34}$ In this context, fear of crime seems to be a motivating force that encourages vigilance. Several studies have assessed the effect of neighborhood characteristics on sleep.
Most of them have used a single aggregate measure of social environment based on a combined index of self-reported perceptions of neighborhood crime, noise, and cleanliness, linking it to self-reported sleep quality. ${ }^{24-26}$ These studies have found that residence in a neighborhood that is perceived as noisy, unclean, and crime-ridden is associated with poorer self-rated sleep quality. These studies also reported that neighborhood distress is associated with poor self-rated physical health and that it was partially mediated by poor sleep quality. ${ }^{24,25}$ It was also reported that the relationship between neighborhood disorder and psychological distress was amplified by poor sleep quality.

Although a large and consistent body of the literature in North America and Europe has found that those living in a disadvantaged neighborhood are at higher risk for poor sleep, there has been only one study (to our knowledge) that has assessed the impact of perceived neighborhood safety on sleep outside the aforementioned regions. ${ }^{33}$ This study found that perceived neighborhood safety was associated with improved sleep quality in Mexico, South Africa, India, China, and Russia. Our study is consistent with some of these findings, with the exception that we found home safety to be a more important safety indicator than neighborhood safety. This could be due the fact that that people who live in unsafe neighborhoods also live in unsafe homes, and, in this scenario, sleep would only be disturbed when it is perceived that the home is unsafe. This finding is very relevant when looking at our prior work, where we found that improvements in sleep quality were possible in even the most disadvantaged neighborhoods after a housing upgrade in slums. ${ }^{28}$ Through qualitative analysis, we found that the improvements in sleep could be attributed to more comfort and a newfound feeling of safety. Our current results suggest that differences in feelings of home safety play a major role in explaining the sleep disparity found between slums and richer neighborhoods.

In one of the best prior studies on this topic, ${ }^{27}$ a safety global score was created based on reports of neighborhood characteristics from people other than those reporting on their sleep habits. Although reducing same source bias, such a design may hamper the ability to assess the very individualized fear of victimization and its impact on sleep. The authors of the aforementioned study reported that low levels of safety from crime were associated with shorter selfreported sleep duration. ${ }^{24}$ The body of literature that has assessed perceived neighborhood violence in terms of short sleep ( $<7$ hours) is less consistent. One study found perceived safe neighborhood to be associated with a reduced risk of short sleep duration in China and Ghana but not in Russia and South Africa. ${ }^{33}$ In contrast, the 
Table 2

The impact of safety on poor sleep quality.

\begin{tabular}{|c|c|c|c|c|c|c|}
\hline & \multirow{2}{*}{$\frac{\text { Model } 1}{\text { OR }(95 \% \mathrm{CI})}$} & \multirow[b]{2}{*}{$P$} & \multirow{2}{*}{$\frac{\text { Model } 2}{\text { OR }(95 \% \mathrm{CI})}$} & \multirow[b]{2}{*}{$P$} & \multirow{2}{*}{$\frac{\text { Model } 3}{\text { OR }(95 \% \mathrm{CI})}$} & \multirow[b]{2}{*}{$P$} \\
\hline & & & & & & \\
\hline Men (reference) & - & - & & & & \\
\hline Women & $\begin{array}{l}1.33 \\
(1.14-1.54)\end{array}$ & $<.001$ & $\begin{array}{l}1.32 \\
(1.14-1.53)\end{array}$ & $<.001$ & $\begin{array}{l}1.31 \\
(1.13-1.52)\end{array}$ & $<.001$ \\
\hline Age, $18-29$ y (reference) & - & - & - & - & - & - \\
\hline Age, 30-39 y & $\begin{array}{l}1.10 \\
(0.88-1.37)\end{array}$ & .380 & $\begin{array}{l}1.10 \\
(0.88-1.37)\end{array}$ & .398 & $\begin{array}{l}1.10 \\
(0.88-1.37)\end{array}$ & .381 \\
\hline Age, $40-49 \mathrm{y}$ & $\begin{array}{l}1.23 \\
(0.98-1.54)\end{array}$ & .072 & $\begin{array}{l}1.22 \\
(0.97-1.53)\end{array}$ & .083 & $\begin{array}{l}1.22 \\
(0.97-1.54)\end{array}$ & .078 \\
\hline Age, 50-64 y & $\begin{array}{l}1.39 \\
(1.12-1.72)\end{array}$ & .003 & $\begin{array}{l}1.39 \\
(1.12-1.73)\end{array}$ & .003 & $\begin{array}{l}1.38 \\
(1.11-1.72)\end{array}$ & .003 \\
\hline Age, $65+y$ & $\begin{array}{l}0.85 \\
(0.66-1.09)\end{array}$ & .224 & $\begin{array}{l}0.88 \\
(0.68-1.12)\end{array}$ & .316 & $\begin{array}{l}0.87 \\
(0.68-1.12)\end{array}$ & .301 \\
\hline Education (years in school) & $\begin{array}{l}0.97 \\
(0.95-0.99)\end{array}$ & .033 & $\begin{array}{l}0.98 \\
(0.96-1.00)\end{array}$ & .075 & $\begin{array}{l}0.98 \\
(0.96-1.00)\end{array}$ & .105 \\
\hline $\begin{array}{l}\text { Neighborhood } \\
\text { non-slum (reference) }\end{array}$ & - & - & - & - & - & - \\
\hline Neighborhood slum & $\begin{array}{l}1.45 \\
(1.03-2.03)\end{array}$ & .032 & $\begin{array}{l}1.43 \\
(1.02-2.01)\end{array}$ & .038 & $\begin{array}{l}1.40 \\
(0.99-1.97)\end{array}$ & .053 \\
\hline Non-obese (reference) & - & - & - & - & & \\
\hline Obese & $\begin{array}{l}1.23 \\
(1.03-1.47)\end{array}$ & .020 & $\begin{array}{l}1.23 \\
(1.03-1.47)\end{array}$ & .021 & $\begin{array}{l}1.23 \\
(1.03-1.46)\end{array}$ & .021 \\
\hline $\begin{array}{l}\text { Safe neighborhood } \\
\text { (Reference) }\end{array}$ & - & - & - & - & & \\
\hline Unsafe neighborhood & - & - & $\begin{array}{l}1.30 \\
(1.12-1.51)\end{array}$ & $<.001$ & $\begin{array}{l}1.12 \\
(0.94-1.35)\end{array}$ & .194 \\
\hline Safe home (reference) & - & - & - & - & - & - \\
\hline Unsafe home & - & - & - & - & $\begin{array}{l}1.32 \\
(1.09-1.59)\end{array}$ & .004 \\
\hline
\end{tabular}

Abbreviation: $C I$, confidence interval.

Binary logistic regression analysis was used to model poor sleep quality as a function of SES markers, obesity, and neighborhood and home safety. Model 1 was adjusted for sex, age, education, neighborhood type, and obesity. Model 2 was adjusted for sex, age, education, neighborhood type, obesity, and neighborhood safety. Model 3 adjusted for sex, age, education, neighborhood type, obesity, and neighborhood and home safety.

same authors found that a safe neighborhood was associated with increased risk of short sleep in India. ${ }^{33}$ Our study is the first to evaluate the impact of safety on sleep duration in Latin America, and, interestingly, we found a higher risk of short sleep among participants who felt unsafe in their home but not in their neighborhood.

Another interesting finding is that slum dwellers are at a lower risk for short sleep compared with those living in more developed neighborhoods. We believe that the lack of a safe and reliable electrical infrastructure and limited access to electronic devices, such as

Table 3

Impact of safety on poor sleep quality in sex-stratified analyses.

\begin{tabular}{|c|c|c|c|c|}
\hline & \multirow{2}{*}{$\frac{\text { Women }}{\mathrm{OR}(95 \% \mathrm{CI})}$} & \multirow[b]{2}{*}{$P$} & \multirow{2}{*}{$\frac{\text { Men }}{\text { OR }(95 \% \mathrm{CI})}$} & \multirow[b]{2}{*}{$P$} \\
\hline & & & & \\
\hline Age 18-29 y (reference) & - & - & - & - \\
\hline Age $30-39$ y & $1.14(0.84-1.55)$ & .391 & $1.10(0.80-1.52)$ & .546 \\
\hline Age $40-49$ y & $1.41(1.04-1.91)$ & .025 & $0.98(0.69-1.40)$ & .949 \\
\hline Age $50-64$ y & $1.51(1.13-2.02)$ & .005 & $1.20(0.85-1.68)$ & .287 \\
\hline Age $65+y$ & $0.93(0.66-1.29)$ & .667 & $0.80(0.54-1.17)$ & .255 \\
\hline Education (years in school) & $0.97(0.94-1.00)$ & .048 & 0.99 (0.96-1.03) & .874 \\
\hline $\begin{array}{l}\text { Neighborhood } \\
\text { non-slum (reference) }\end{array}$ & - & - & - & - \\
\hline Neighborhood slum & $1.77(1.16-2.71)$ & .007 & $0.89(0.47-1.68)$ & .729 \\
\hline Non-obese (reference) & - & - & - & - \\
\hline Obese & $1.55(1.23-1.94)$ & .000 & $0.81(0.60-1.09)$ & .180 \\
\hline $\begin{array}{l}\text { Safe neighborhood } \\
\text { (reference) }\end{array}$ & - & - & - & - \\
\hline Unsafe neighborhood & $1.25(0.98-1.60)$ & .070 & $0.99(0.76-1.31)$ & .995 \\
\hline Safe home (reference) & - & - & - & - \\
\hline Unsafe home & $1.38(1.08-1.78)$ & .010 & $1.19(0.88-1.61)$ & .253 \\
\hline
\end{tabular}

Binary logistic regression analysis was used to model poor sleep quality as a function of SES markers, obesity, and both neighborhood and home safety. The model was adjusted for age, education, neighborhood type, obesity, and neighborhood and home safety. laptops/smart phones/tablets, could explain a longer sleep duration. ${ }^{35}$ Poor sleep quality in slums may also explain the need for a longer sleep, as well of depression and hopelessness. ${ }^{28,36} \mathrm{At}$ the same time, for middle- (and sometimes low-) income families, it is very common to look for better schools outside their neighborhood, pushing parents' wake times earlier. ${ }^{37}$

An additional important finding from our work was that the impact of safety on sleep quality was greater among women than men, suggesting that women are more susceptible to the sleep effects of feeling unsafe. An explanation for this could be that women are also at higher risk than men for depression and anxiety, which are known risk factors for insomnia. ${ }^{38,39}$ It has also been shown that women have a higher sense of threat compared with men. ${ }^{40}$ Our sex-based sleep findings are consistent with a study conducted in North America that found women who experienced exposure to high neighborhood violence had greater odds of reporting less than seven hours of sleep per night. ${ }^{34}$

All of the studies that have assessed crime safety and sleep have been done in North America and Europe with the exception of one. ${ }^{33}$ Our study is the first one to assess both sleep duration and quality in Latin America, a region haunted by increasing rates of criminality. The only other study conducted in Latin America reported that poor sleep was associated with low neighborhood safety but did not report on sleep duration or on sex differences. ${ }^{33}$

Unlike most of the prior work on safety and sleep, our study was able to separate the impact of home safety from neighborhood conditions in general. Our results suggest that home safety is more relevant to sleep than neighborhood safety in general and that prior work associating neighborhood sleep was likely confounded by the lack of consideration to home conditions. The impact of home safety may be magnified in this study compared with prior work because Latin 
The impact of safety on self-reported sleep duration.

\begin{tabular}{|c|c|c|c|c|c|c|c|c|c|c|c|c|}
\hline & \multicolumn{4}{|l|}{ Model 1} & \multicolumn{4}{|l|}{ Model 2} & \multicolumn{4}{|l|}{ Model 3} \\
\hline & \multirow{2}{*}{$\frac{<7 \mathrm{~h} \text { of sleep }}{\mathrm{OR}(95 \% \mathrm{CI})}$} & \multirow[b]{2}{*}{$P$} & \multirow{2}{*}{$\frac{>8 \text { h of sleep }}{\text { OR }(95 \% \mathrm{CI})}$} & \multirow[b]{2}{*}{$P$} & \multirow{2}{*}{$\frac{<7 \text { h of sleep }}{\text { OR }(95 \% \mathrm{CI})}$} & \multirow[b]{2}{*}{$P$} & \multirow{2}{*}{$\frac{>8 \text { h of sleep }}{\text { OR }(95 \% \mathrm{CI})}$} & \multirow[b]{2}{*}{$P$} & \multirow{2}{*}{$\frac{<7 \text { h of sleep }}{\text { OR }(95 \% \mathrm{CI})}$} & \multirow[b]{2}{*}{$P$} & \multirow{2}{*}{$\frac{>8 \mathrm{~h} \text { of sleep }}{\text { OR }(95 \% \mathrm{CI})}$} & \multirow[b]{2}{*}{$P$} \\
\hline & & & & & & & & & & & & \\
\hline $\begin{array}{l}\text { Men } \\
\text { (reference) }\end{array}$ & - & - & - & - & - & - & - & - & - & - & - & - \\
\hline Women & $\begin{array}{l}0.69 \\
(0.60-0.79)\end{array}$ & $<.001$ & $\begin{array}{l}1.26 \\
(1.0-1.46)\end{array}$ & .001 & $\begin{array}{l}0.69 \\
(0.61-0.79)\end{array}$ & $<.001$ & $\begin{array}{l}1.25 \\
(1.08-1.45)\end{array}$ & .002 & $\begin{array}{l}0.69 \\
(0.61-0.79)\end{array}$ & $<.001$ & $\begin{array}{l}1.25 \\
(1.08-1.45)\end{array}$ & .003 \\
\hline $18-29 y$ & - & - & - & - & - & - & - & - & - & - & - & - \\
\hline $30-39 y$ & $\begin{array}{l}1.100 \\
(0.90-1.33)\end{array}$ & .335 & $\begin{array}{l}0.51 \\
(0.41-0.63)\end{array}$ & $<.001$ & $\begin{array}{l}1.10 \\
(0.91-1.34)\end{array}$ & .303 & $\begin{array}{l}0.52 \\
(0.41-0.65)\end{array}$ & $<.001$ & $\begin{array}{l}1.11 \\
(0.92-1.35)\end{array}$ & .264 & $\begin{array}{l}0.52 \\
(0.41-0.65)\end{array}$ & $<.001$ \\
\hline $40-49 y$ & $\begin{array}{l}1.30 \\
(1.06-1.61)\end{array}$ & .012 & $\begin{array}{l}0.64 \\
(0.51-0.81)\end{array}$ & $<.001$ & $\begin{array}{l}1.324 \\
(1.07-1.63)\end{array}$ & .009 & $\begin{array}{l}0.66 \\
(0.52-0.83)\end{array}$ & .001 & $\begin{array}{l}1.33 \\
(1.08-1.64)\end{array}$ & .007 & $\begin{array}{l}0.66 \\
(0.52-0.83)\end{array}$ & .001 \\
\hline $50-64$ y & $\begin{array}{l}0.853 \\
(0.69-1.04)\end{array}$ & .121 & $\begin{array}{l}0.53 \\
(0.43-0.66)\end{array}$ & $<.001$ & $\begin{array}{l}0.85 \\
(0.70-1.05)\end{array}$ & .137 & $\begin{array}{l}0.54 \\
(0.43-0.67)\end{array}$ & $<.001$ & $\begin{array}{l}0.86 \\
(0.70-1.05)\end{array}$ & .145 & $\begin{array}{l}0.54 \\
(0.43-0.67)\end{array}$ & $<.001$ \\
\hline $65+y$ & $\begin{array}{l}0.71 \\
(0.57-0.89)\end{array}$ & .003 & $\begin{array}{l}0.98 \\
(0.79-1.22)\end{array}$ & .916 & $\begin{array}{l}0.72 \\
(0.57-0.90)\end{array}$ & .004 & $\begin{array}{l}1.02 \\
(0.82-1.28)\end{array}$ & .799 & $\begin{array}{l}0.72 \\
(0.57-0.90)\end{array}$ & .004 & $\begin{array}{l}1.02 \\
(0.82-1.28)\end{array}$ & .811 \\
\hline Education (years in school) & $\begin{array}{l}0.98 \\
(0.96-0.99)\end{array}$ & .029 & $\begin{array}{l}0.91 \\
(0.90-0.93)\end{array}$ & $<.001$ & $\begin{array}{l}0.97 \\
(0.95-0.99)\end{array}$ & .013 & $\begin{array}{l}0.91 \\
(0.89-0.93)\end{array}$ & $<.001$ & $\begin{array}{l}0.97 \\
(0.96-0.99)\end{array}$ & .024 & $\begin{array}{l}0.91 \\
(0.90-0.93)\end{array}$ & $<.001$ \\
\hline $\begin{array}{l}\text { Neighborhood non-slum } \\
\text { (Reference) }\end{array}$ & - & - & - & - & - & - & - & - & - & - & - & - \\
\hline Neighborhood slum & $(0.40-0.85)$ & .005 & $\begin{array}{l}1.04 \\
(0.73-1.49)\end{array}$ & .803 & $\begin{array}{l}0.58 \\
(0.40-0.84)\end{array}$ & .005 & $\begin{array}{l}1.04 \\
(0.73-1.49)\end{array}$ & .805 & $\begin{array}{l}0.57 \\
(0.39-0.83)\end{array}$ & .004 & $\begin{array}{l}1.03 \\
(0.72-1.48)\end{array}$ & .834 \\
\hline $\begin{array}{l}\text { Non-obese } \\
\text { (reference) }\end{array}$ & - & - & - & - & - & - & - & - & - & - & - & - \\
\hline Obese & $\begin{array}{l}1.08 \\
(0.91-1.28)\end{array}$ & .344 & $\begin{array}{l}1.22 \\
(1.01-1.47)\end{array}$ & .031 & $\begin{array}{l}1.10 \\
(0.92-1.31)\end{array}$ & .267 & $\begin{array}{l}1.22 \\
(1.01-1.48)\end{array}$ & .031 & $\begin{array}{l}1.10 \\
(0.92-1.31)\end{array}$ & .267 & $\begin{array}{l}1.22 \\
(1.01-1.47)\end{array}$ & .032 \\
\hline $\begin{array}{l}\text { Safe neighborhood } \\
\text { (reference) }\end{array}$ & & & & & - & - & - & - & - & - & - & - \\
\hline Unsafe neighborhood & & & & & $\begin{array}{l}0.94 \\
(0.82-1.08)\end{array}$ & .431 & $\begin{array}{l}0.98 \\
(0.85-1.14)\end{array}$ & .841 & $\begin{array}{l}0.85 \\
(0.73-1.00)\end{array}$ & .060 & $\begin{array}{l}0.95 \\
(0.80-1.13)\end{array}$ & .589 \\
\hline $\begin{array}{l}\text { Safe home } \\
\text { (reference) }\end{array}$ & & & & & & & & & - & - & - & - \\
\hline Unsafe home & & & & & & & & & $\begin{array}{l}1.23 \\
(1.03-1.48)\end{array}$ & .020 & $\begin{array}{l}1.07 \\
(0.88-1.30)\end{array}$ & .473 \\
\hline
\end{tabular}

Multinomial logistic regression analysis was used to assess the effect of SES markers (and obesity) on sleep duration as well as neighborhood and home safety. Sleep duration was categorized as follows: "less than 7 hours," "7-8 hours (reference)," and "more than 8 hours." Model 1 was adjusted for sex, age, education, neighborhood type, and obesity. Model 2 was adjusted for sex, age, education, neighborhood type, obesity, and neighborhood safety. Model 3 was adjusted for sex, age, education, neighborhood type, obesity, and neighborhood and home safety. For each variable, the OR reflects the odds that an individual with that factor has short (or long) sleep duration relative to an intermediate sleep duration as compared with an individual with the reference value for that factor.

America is a region with much greater rates of crime and greater concerns for safety in general compared with North America or Europe, and, in this scenario, home safety may outweigh neighborhood environment effects on sleep. For instance, the victimization rate, which is the percentage of households in which at least one member was a victim of crime over the prior year, was $30.5 \%$ in South America in 2008 vs $14.9 \%$ for the United States (2010). ${ }^{41}$

Several limitations of our work should be noted. The measures of safety both in the neighborhood and in the home were simple singleitem measures that have not been fully validated. A second limitation of this study is that it relied on responses to both sleep and safety questions from each participant, which may lead to same-source bias. ${ }^{42} \mathrm{Fu}-$ ture studies should address this issue by acquiring safety data through other sources than the participant being studied and/or use objective measurements of sleep, such as those collected with actigraphy or polysomnography. Another important limitation of our study is lack of information about depression or other mental health measures that may mediate or moderate effects of safety on sleep.

Multisectoral holistic approaches that address effectively social, political, and economic causes of crime are therefore needed to improve feelings of safety. A systematic review on environmental interventions to reduce fear of crime in countries of the Organization for Economic Cooperation and Development (OECD) found evidence to be inconclusive, although some interventions might have potential to reduce fear of crime. ${ }^{43}$ The authors of the study concluded that the most promising intervention was enabling "home improvements," which aligns with our previous results in a non-OECD country (Argentina). ${ }^{28,43}$
There is limited evidence that neighborhood social cohesion might reduce the impact of an adverse neighborhood on sleep and health. ${ }^{9,13,44,10}$ Nevertheless, social cohesion-oriented interventions coupled with environmental interventions could potentially mitigate the effect of fear of crime on sleep and health. Further research is warranted to assess whether interventions addressing crime safety can be used to improve sleep and overall health. Until then, it would seem that crime and violence will continue to generate societal unrest in the most literal sense.

\section{Conclusion}

Our primary finding suggests that feeling unsafe in the home is associated with poor sleep quality and shorter sleep duration, and this association is more pronounced among women. In contrast, after accounting for home safety, no independent association was found between neighborhood safety and sleep. Future studies on crime safety should separately consider the impact of home and neighborhood safety and evaluate for differences in susceptibility by sex.

\section{Disclosure statement}

Dr. Patel reports personal fees from Apnicure, personal fees from Apnex Medical, personal fees from Vertex Pharmaceuticals, outside the submitted work. The rest of the authors have nothing to disclose. 


\section{Acknowledgments}

We wish to thank Graciela Romanelli for her technical assistance. Data used herein were provided by the ASDO (Observatorio de la Deuda Social Argentina) through de Argentine Social Debt Survey (Encuesta sobre de la Deuda Social Argentina).

\section{References}

1. Pickett KE, Pearl M. Multilevel analyses of neighbourhood socioeconomic context and health outcomes: a critical review. J Epidemiol Community Health. 2001;55:111-122.

2. Chaix B. Geographic life environments and coronary heart disease: a literature review, theoretical contributions, methodological updates, and a research agenda. Annu Rev Public Health. 2009;30:81-105.

3. Auchincloss AH, Diez Roux AV, Mujahid MS, Shen M, Bertoni AG, Carnethon MR. Neighborhood resources for physical activity and healthy foods and incidence of type 2 diabetes mellitus: the Multi-Ethnic Study of Atherosclerosis. Arch Intern Med. 2009;169:1698-1704

4. Leal C, Chaix B. The influence of geographic life environments on cardiometabolic risk factors: a systematic review, a methodological assessment and a research agenda. Obes Rev. 2011;12:217-230.

5. Unger E, Diez-Roux AV, Lloyd-Jones DM, et al. Association of neighborhood characteristics with cardiovascular health in the multi-ethnic study of atherosclerosis. Circ Cardiovasc Qual Outcomes. 2014;7:524-531.

6. Diez Roux AV. Residential environments and cardiovascular risk. J Urban Health. 2003;80:569-589.

7. Dannenberg AL, Jackson RJ, Frumkin $\mathrm{H}$, et al. The impact of community design and land-use choices on public health: a scientific research agenda. Am J Public Health. 2003;93:1500-1508.

8. Schootman M, Andresen EM, Wolinsky FD, et al. The effect of adverse housing and neighborhood conditions on the development of diabetes mellitus among middleaged African Americans. Am J Epidemiol. 2007;166:379-387.

9. Mujahid MS, Diez Roux AV, Morenoff JD, et al. Neighborhood characteristics and hypertension. Epidemiology. 2008;19:590-598.

10. Mujahid MS, Diez Roux AV, Shen M, et al. Relation between neighborhood environments and obesity in the Multi-Ethnic Study of Atherosclerosis. Am J Epidemiol. 2008;167:1349-1357.

11. Miranda ML, Edwards SE, Anthopolos R, Dolinsky DH, Kemper AR. The built environment and childhood obesity in Durham, North Carolina. Clin Pediatr (Phila). 2012;51:750-758

12. Ellaway A, Macintyre S, Bonnefoy X. Graffiti, greenery, and obesity in adults: secondary analysis of European cross sectional survey. BMJ. 2005;331:611-612.

13. Agyemang C, van HC, Wendel-Vos W. Ethnic differences in the effect of environmental stressors on blood pressure and hypertension in the Netherlands. BMC Public Health. 2007;7:118.

14. Alegria M, Molina KM, Chen CN. Neighborhood characteristics and differential risk for depressive and anxiety disorders across racial/ethnic groups in the United States. Depress Anxiety. 2014;31(1):27-37.

15. Colten HR, ABe. Sleep disorders and sleep deprivation: an unmet public health problem. The National Academies Collection: reports funded by National Institutes of Health; 2006.

16. Patel SR, Hayes AL, Blackwell T, et al. The association between sleep patterns and obesity in older adults. Int J Obes (Lond). 2014;38:1159-1164.

17. Patel SR, Hu FB. Short sleep duration and weight gain: a systematic review. Obesity (Silver Spring). 2008;16:643-653.

18. Van CE, Spiegel K, Tasali E, Leproult R. Metabolic consequences of sleep and sleep loss. Sleep Med. 2008;9(Suppl 1):S23-S28.

19. Tasali E, Leproult R, Spiegel K. Reduced sleep duration or quality: relationships with insulin resistance and type 2 diabetes. Prog Cardiovasc Dis. 2009;51:381-391.

20. Wiebe ST, Cassoff J, Gruber R. Sleep patterns and the risk for unipolar depression: a review. Nat Sci Sleep. 2012;4:63-71.
21. Spilsbury JC, Storfer-Isser A, Kirchner HL, et al. Neighborhood disadvantage as a risk factor for pediatric obstructive sleep apnea. J Pediatr. 2006;149:342-347.

22. Brouillette RT, Horwood L, Constantin E, Brown K, Ross NA. Childhood sleep apnea and neighborhood disadvantage. J Pediatr. 2011;158:789-795.

23. Ralls FM, Grigg-Damberger M. Roles of gender, age, race/ethnicity, and residential socioeconomics in obstructive sleep apnea syndromes. Curr Opin Pulm Med. 2012; 18:568-573.

24. Hale L, Hill TD, Burdette AM. Does sleep quality mediate the association between neighborhood disorder and self-rated physical health? Prev Med. 2010;51: 275-278.

25. Hale L, Hill TD, Friedman E, et al. Perceived neighborhood quality, sleep quality, and health status: evidence from the Survey of the Health of Wisconsin. Soc Sci Med. 2013;79:16-22.

26. Hill TD, Burdette AM, Hale L. Neighborhood disorder, sleep quality, and psychological distress: testing a model of structural amplification. Health Place. 2009;15: 1006-1013.

27. Desantis AS, Diez Roux AV, Moore K, Baron KG, Mujahid MS, Nieto FJ. Associations of neighborhood characteristics with sleep timing and quality: the Multi-Ethnic Study of Atherosclerosis. Sleep. 2013;36:1543-1551.

28. Simonelli G, Leanza Y, Boilard A, et al. Sleep and quality of life in urban poverty: the effect of a slum housing upgrading program. Sleep. 2013;36:1669-1676.

29. Corporación Latinobarómetro. 2010 report: Latinobarómetro. Santiago de Chile: Latinobarómetro; 2010.

30. Lupton D, Tulloch J. Theorizing fear of crime: beyond the rational/irrational opposition. Br J Sociol. 1999;50:507-523.

31. Alegria M, Molina KM, Chen CN. Neighborhood characteristics and differential risk for depressive and anxiety disorders across racial/ethnic groups in the United States. Depress Anxiety. 2014;31:27-37.

32. Matheson FI, Moineddin R, Dunn JR, Creatore MI, Gozdyra P, Glazier RH. Urban neighborhoods, chronic stress, gender and depression. Soc Sci Med. 2006;63: 2604-2616.

33. Hill T, Trinh HN, Wen M, Hale L. Perceived neighborhood safety and sleep quality: a global analysis of six countries. Sleep Med. 2014 in press].

34. Salminen S, Oksanen T, Vahtera J, et al. Sleep disturbances as a predictor of occupational injuries among public sector workers. J Sleep Res. 2010;19:207-213.

35. Gradisar M, Wolfson AR, Harvey AG, Hale L, Rosenberg R, Czeisler CA. The sleep and technology use of Americans: findings from the National Sleep Foundation's 2011 Sleep in America poll. J Clin Sleep Med. 2013;9:1291-1299.

36. Mair C, Kaplan GA, Everson-Rose SA. Are there hopeless neighborhoods? An exploration of environmental associations between individual-level feelings of hopelessness and neighborhood characteristics. Health Place. 2012;18:434-439.

37. Vigo DE, Simonelli G, Tuñón I, Perez-Chada D, Cardinali DP, Golombek D. School characteristics, child work, and other daily activities as sleep deficit predictors in adolescents from households with unsatisfied basic needs. Mind Brain Educ. 2014;8:175-181.

38. McLean CP, Asnaani A, Litz BT, Hofmann SG. Gender differences in anxiety disorders: prevalence, course of illness, comorbidity and burden of illness. J Psychiatr Res. 2011;45:1027-1035

39. van Mill JG, Hoogendijk WJ, Vogelzangs N, van DR, Penninx BW. Insomnia and sleep duration in a large cohort of patients with major depressive disorder and anxiety disorders. J Clin Psychiatry. 2010;71:239-246.

40. Solomon Z, Gelkopf M, Bleich A. Is terror gender-blind? Gender differences in reaction to terror events. Soc Psychiatry Psychiatr Epidemiol. 2005;40:947-954.

41. OAS Hemispheric Security Observatory. Report on citizen security in the Americas 2012: official statistical information on citizen security provided by the OAS member states. Washington DC: OAS Secretariat for Multidimensional Security; 2012.

42. Hill T, Maimon D. Neighborhood context and mental health. In: Aneshensel C, Birman A, Phelan J, editors. Handbook of the sociology of mental health. New York: Springer; 2013. p. 479-501.

43. Lorenc T, Petticrew M, Whitehead M, et al. Environmental interventions to reduce fear of crime: systematic review of effectiveness. Syst Rev. 2013;2:30.

44. Chen-Edinboro LP, Kaufmann CN, Augustinavicius JL, et al. Neighborhood physical disorder, social cohesion, and insomnia: results from participants over age 50 in the Health and Retirement Study. Int Psychogeriatr. 2014;15:1-8. 